\title{
Neoliberal Gremlins? How a scheme to help disadvantaged young people thrive online fell short of its ambitions.
}

Huw C. Davies, Rebecca Eynon, Sarah Wilkin

\begin{abstract}
Numerous academic studies highlight the significant differences in the ways that young people access, use and engage with the Internet and the implications it has in their lives. Trying to address such inequalities is complex and the outcomes of digital inclusion schemes are rarely uniformly positive or transformative for the people involved. Therefore the hope of such schemes, that if sufficiently empowered, incentivised and aspirational the disadvantaged can use access to technology to transform or transcend what Bourdieu (1992) calls their “class of conditions” (p53), is largely misplaced.

This gap between expectation and reality demands theoretical attention. Focusing on a two-year digital inclusion scheme for 30 teenagers and their families in one area of England, this qualitative study analyses why, despite the good intentions of the scheme's stakeholders, it fell short of its ambitions. Instead, our theoretical analysis explains how the neoliberalist systems of governance that are increasingly shaping the cultures and behaviours of our Internet service providers and schools cannot solve the problems they create.
\end{abstract}

\section{Key Words}

Digital inequality, digital inclusion, neoliberalism, governmentality, education, youth

\section{Introduction}

The exoticising rhetoric around the 'born digital' generation is well recognised. Despite the numerous academic outputs that have rejected the notion both conceptually and 
empirically (e.g. Bennett, Maton \& Kervin, 2008; Helsper \& Eynon, 2010); the belief that young people are uniquely engaged with digital technology still distracts practitioners and policy makers from fully addressing the unequal distribution of access to the Internet and skills, and opportunities online.

Indeed, numerous academic studies highlight the significant differences in the ways that young people access and use the Internet, and how it impacts their lives (boyd, 2014; Livingstone \& Helsper, 2007). Furthermore, despite the move towards richer and more complex models of digital inclusion that include skills and level of engagement (Hargittai, 2010; Hargittai \& Shaw 2014) quality of access (as measured by availability of device and network, and degree of personalisation) remains critical. While the majority of young people have some form of access to the Internet, for some their connections are sporadic, dependent on credit on their phones, an available library, or Wi-Fi open to the public. Qualitative data in a variety of countries has shown such limited forms of access can create difficulties for these young people as an Internet connection becomes essential for socialising, accessing public services, saving money, and learning at school (Davies \& Eynon, 2013; Facer \& Furlong, 2001; Robinson et al. 2015).

The more optimistic literature about young people’s access and skills deficits implies that if sufficiently empowered, incentivised, and aspirational socially and economically disadvantaged people can use their access to networked technology to transform or at least begin to transcend their socio-economic situation or what Bourdieu calls their “class of conditions” (Bourdieu, 1992, p. 53). The UK government seems to agree. It has financed technological infrastructure and invested in schemes to address digital inequalities (e.g. Jewitt \& Parashar 2011). There is, however, a significant history of providing young people with access to technical devices to address issues of 
both digital and educational inequality across the world that challenges the assumed relationship between digital technology and socio-economic progress. These include the one laptop per child initiative across countries primarily in the global south, federal and state digital inclusion programmes in the US. Beyond practical factors that could potentially be improved (better quality devices or targeted skills training), all these initiatives in some way have been unable to accommodate the multifaceted realities of people's lives suggesting that more attention needs to be placed on the cultural, political and economic context (Selwyn, 2014; Straubhaar et al., 2012). In this paper we aim to contribute to this debate by moving beyond the practical and material choices that were made about one particular home Internet access initiative in the UK and attend instead to how the current political and social milieu was unhelpfully structured into the scheme.

In the discussion below, we show that fundamental tensions in this two-year programme summoned tacitly accepted neoliberal principles and practices which occluded the translation of goodwill into a successful philanthropic enterprise. Because it is a concept that is often over-used or deployed with a lack of rigour, we acknowledge that evoking neoliberalism is problematic. However, we argue these principles amounted to neoliberalism in action and, in microcosm, the project demonstrates how the practices (and mind-set they create) are preventing schools and digital service providers from helping to reduce inequalities. Indeed, we found these principles incentivised action that is counterproductive to addressing digital inequality and practices that are incapable of resolving the problems they create.

Specifically, Foucault's articulation of neoliberalism gives a framework to critically assess the challenges and realities of this scheme as it encountered the structures, cultures, and practices of the institutions that govern the lives of 
disadvantaged people in England today. This application of theory to our data allows us to show in wealthy post-industrial economies the global networked society is not "simply a fact - that is, as something that is just given and therefore inevitable: it as a choice, a choice made by some and working in the interest of some” (Biesta, 2013, p.734). However, this 'working in the interest of some’ implies some top-down coordination. The form of neoliberalism that emerges from our data militates against the promise of technology to transform people's lives by excluding them from the global networked society but not through the coordinated deliberate top-down exercise of power. Rather we show inequality is compounded by the 'mentalities of government' (Dean, 1999, p.16) that produce the institutional regimes, knowledges, practices and procedures that 'internalise and normalise the exercise power over and through certain sectors of society' (Wyn \& White, 1997, p.133). In effect, this means that although we tried to involve and empower the families in the scheme, in the end it was done to them and the people working for institutions involved in the scheme were unable or unwilling to remedy this.

\section{The Home Access Scheme}

The project was initiated by the local council, due to its concerns about the links between digital and social disadvantage. It was estimated that around $10 \%$ of young people in the local area who were in year 9 (aged 13) were without dependable access to the Internet and had no laptop or pc at home. Because they were beginning their GCSEs ${ }^{1}$, this lack of access was considered potentially damaging for educational attainment. After approaching the research team, the project mobilised three state

1 The General Certificate of Secondary Education (GCSEs) are public examinations taken by 16 year olds in England and Wales. They typically include Mathematics, English, Sciences and a number of other subjects as selected by the student. 
schools, and procured the services of an Internet Service Provider (ISP) to provide thirty young people (and their families) with a free laptop, a free broadband connection or mobile dongle, technical support, and in-school skills training and support for two years. From its inception the project's objectives were:

“To raise attainment in target students in GCSE's in 2016 and also increase social confidence and ability to use the Internet post school to help them seek out employment. It will also assist them in learning some of the key elements outlined in the new National Curriculum, in particular to help them 'be responsible, competent, confident and creative users of information and communications technology'.”

Yet this compact and direct statement obscures the more complex assumptions about the project outcomes held by the various stakeholders involved with the project. This is an issue we return to below.

The initiative was designed as a collaborative project. The council was responsible for procuring the Internet services for the families and co-ordinating the work across the schools. The schools were liable for procuring the laptops, memory sticks and software for the students, providing regular structured in-school pastoral, skills and technical support, liaising with the families and providing the research team with access to the students and their school data to support the evaluation. Through a focus both on schoolwork and personal interest, the support was designed to advance the students' critical, social, creative and technical skills (Livingstone, 2008). The research team were initially responsible for providing research-informed expertise at all stages of the project, supporting the lead teachers from each of the schools and formally evaluating the project. However, this role did shift, and the research team was ultimately the main liaison with the families and the provider of the skills training in the 
schools. The ISP provider was employed by the council to offer a tailored support scheme to each of the families who wanted to have broadband Internet access, including a set up visit and a helpline throughout the project.

\section{Methodology}

According to the original plan developed by the research team in partnership with the schools and the council this was going to be a mixed method case study involving before and after interviews, a short survey with all thirty students, before and after comparisons of school data about each student, and exit interviews with parents and teachers involved with the scheme, the ISP provider and the council. The goals of the research were to explore the different stakeholders' experiences, document the scheme's practical challenges and successes and map its influence on the young people’s academic performance and behaviour (as measured by school data and teacher assessment) as well as their digital skills, attitudes to the Internet and its use to achieve their personal goals.

In reality, this mixed method evaluative design became a qualitative, ethnographically informed case study. While there were practical reasons for this methodological change of plan (e.g. ultimately, all three schools withheld the student data that had been agreed at the start of the project) it was mainly a consequence of the research team's transformation from the scheme's evaluator to being its project manager, training provider, and technical trouble-shooter.

As will be seen below, this reorientation had significant implications for the research team's level of engagement in this initiative; their level of investment in 'making it work', and the way that other stakeholders came to perceive the team. Research like this, particularly studies that are closer to everyday practice and focus on disadvantaged groups, rarely goes to plan (Walling, 2009): this project was typical. 
However, despite the unanticipated change, to explore the everyday practices and experiences of the stakeholders involved in the project, and enable the development of the theoretical contribution of the study (Swanborn, 2010; Stake, 1995) the qualitative stance of the research was entirely appropriate.

The three state schools engaged with the project were all non-selective and therefore mixed ability. There were differences in each school's catchment area, cohort and the sets of on-going issues that its management were trying to address. For example, School 'Red' is an oversubscribed high achieving school, which has a primarily affluent catchment area, but with a small proportion of young people from economically disadvantaged homes. School 'Yellow' attracts a diverse cohort of students including many with English as an additional language and in receipt of Pupil Premium $^{2}$. School 'Blue’ serves an area of significant social disadvantage; just under half of students are from among the most deprived wards in the country.

Via a combination of surveys, interviews and informal conversations with students and staff, the research team worked with schools to assess students who would benefit from the scheme. Due to the varied 'technological careers' many students experience; where access and use of technology at home may vary considerably over time, the distinction between eligible and ineligible students was blurred and difficult to define. Therefore, this study represents a snapshot of who was considered 'most eligible’ within the three GCSE cohorts when the project began in 2014.

The young people who were part of this scheme were typically from low-income households and / or within which parents / guardians did not use the Internet. They were a diverse group; evenly split in gender balance, with a broad range of educational

\footnotetext{
${ }^{2}$ The Pupil Premium is additional funding for publicly funded schools in England designed to help raise the attainment of disadvantaged pupils and close the gap between them and their peers.
} 
abilities, and some students with English as their second language. All the scheme's students were about to begin their two-year programme for studying for their GCSEs so were they were 13 or 14 years old. They often qualified for Pupil Premium or free school meals. Family arrangements were multiple; some young people were from two parent households, others from single parent households, a few lived with extended family or carers, and one student was from a traveller community. Some, but not all of the families, could be considered 'hard to reach' for studies of this kind (e.g. families where the first language at home is not English), and we were privileged to work with them over the course of the project. In the discussion below we use pseudonyms for each participant that reflect their gender and ethnicity.

Over the two years of the project we employed a range of data collection methods to best capture the rich context surrounding the scheme. The analysis here focuses on the data collected from recorded workshops and one-to-one skills sessions with students and semi-structured interviews with lead teachers, parents and council/community staff. In total, the research team carried out 83 individual consultations in schools with the students to offer skills training, 19 interviews with students and parents at home, 4 interviews with leader teacher(s) (one school shared the role between 2 teachers). We also recorded the insights from 2 community workers and 1 volunteer who works for the project’s ISP. Many other data sources have indirectly informed the analysis presented here. These include notes from meetings with teachers, school leaders, other representatives of the ISP provider and the council; emails between all the stakeholders working on the project, text messages and phone calls between the research team and parents, materials produced for the council, and resources for ICT lessons produced by the schools for the students on the scheme. 
Our transition, relatively early on in the project, from the role of the 'outsider' to the position of the 'insider' meant we came to be perceived as the scheme's architects and proprietors. This had significant implications for our engagements with all the other stakeholders in the project and the data that was constructed through these interactions. The complexity of this project was compounded by working with hard to reach families, the asymmetric power relationships between different parties, the important but challenging distinction between consenting to be part of the initiative and consenting to be part of the research, and our frustration with the ISP's, schools', and the council's gradual disengagement from the project (and our desire to 'make it work' despite this). For example, where once the schools, the ISP, and the council considered us as simply providing useful support and information through a cooperative appraisal process, we were now seen as project's exponents. Furthermore, many of the families were quite accustomed to outsiders (e.g. social workers) coming in and asking them to supply information, and in our interviews family members very quickly volunteered very private details to the research team about their lives that may more reflect how they perceived the research team than they desire for us to use this data directly in the writing up of this study.

In engaging with this research project we have tried to be as reflexive as possible throughout the study in ways that help to produce 'better' research (Pillow, 2003). All interviews were recorded and transcribed for analysis. We made summaries of all meetings and we collected all the email and texts interactions. To actively encourage reflexivity in the analysis and reporting of the study, we made reflective notes about these interactions. Each week the research team met to discuss the interactions with the other stakeholders and our experiences of and perspectives on those events. However, such activities certainly did not address all the messiness of the 
analysis, and despite the relatively 'neat’ story presented below we very much concur with the necessity and reality of 'uncomfortable' reflexivity (Pillow, 2003).

The resulting data (transcripts, notes and reflections) were thematically analysed (Dey, 2003; Miles \& Huberman, 1984). The framing that we present in this paper helped the team to theorise the study, as it emerged inductively from the data analysis. In the writing up of the analysis we have relied to quite a significant extent on description as opposed to direct quotes from participants and we have been very conscious of withholding significant personal information from the participants. This is a deliberate choice to protect and respect our participants' anonymity as far as is possible, while giving space in discussions of digital and social inequality to the experiences of digitally disadvantaged young people and their families.

\section{The project's successes}

In its initial proposals the council set out some relatively clear but broad goals for what 'success' meant for this initiative. It moved beyond counts of numbers of families with a laptop and Internet connection working at home, towards the impact of the home connection on young people's digital skills and uses of the Internet for their academic and social lives as well as their and plans for future employment.

Similar objectives were reflected in the discussions between the schools, council and the research team prior to the project's initiation. It is difficult to ascertain individually held views in group discussions; but ostensibly the group’s ambitions were relatively realistic. The group recognised that such a scheme, even at its very best, could only aim towards offering young people with equal opportunities to access and use technology for learning and everyday life. Such a scheme could never provide equity of life chances or outcomes for young people (Selwyn 2014a; Warschauer, 2004). Yet, in a technologically mediated world access to the Internet can be seen as “a fundamental and 
necessary (though not sufficient) condition for effective personal achievement and social participation, in whatever contexts and to whatever degree people consider important” (Lievrouw \& Farb, 2003, p.503). If young people are set homework that needs a laptop and Internet connection, or all their friends are using Facebook to set up a social event over a weekend, or their careers advice or health information is primarily available online, then having home access matters to them.

Based on the qualitative data from the young people and the families involved with the scheme, in these broad terms the initiative had a reasonable share of 'success'. For some students, the new changes in their home learning environment meant that they felt more motivated to complete their homework and make progress in their subjects. As Katie explained, she was able to catch up with missed work and revise for her exams in her own time and in the comfort of her own home; before she had to go over to a relative’s house or the library. Personalised home access had helped her to "become more confident in school” and become "willing to get involved”. Likewise, for Georgia, who speaks English as her second language, acquiring access to online translation tools enabled her to gain a better understanding of the work teachers set her as she was able to look-up unfamiliar words and read about them in their context.

The affordances of a laptop were an important benefit for some young people. In many ways, this appeared almost as essential to the participants as access to the Internet itself. For example, Brandon explained that there are some homework tasks such as working through units on MyMaths (a maths support website) that are just impossible to complete on a mobile phone: “you need a bigger screen like on the laptops”. And Tilda explained, “I feel more free because I can actually use it more. I don’t feel as restricted as much as when I used my phone”. 
The social affordances of the scheme were clearly the most significant for some. For example, Eden and her family subscribed to NetFlix (an online library of films and television programmes). As a consequence, she could contribute to conversations among her friends about popular media and trends, which was impossible before, as she had no TV. Several of the students explained how, since gaining Internet access, they had been able to use online social networks to develop their existing relationships with friends and family. For example, Ellie explained that she had family living in multiple locations across the UK but no easy way of visiting them. Having access to Facebook and Skype meant that she could cultivate online relationships with these relatives; something which she deemed crucial in the lead up to when she would eventually see them face-to-face.

Domestic family interactions and conversations were also critical. Hannah was a single-parent mum who was living in temporary housing. Her daughter Tilda was looking for career in textiles and fashions as an escape route from the low-wage service labour her mum had to do. They looked at things online together, and Hannah was beginning to develop her own IT skills. As she explained,

"I kind of just learn little bits at a time, like myself, I've only just started for the first time I did some Internet shopping on my own without having to go, "Tilda, what's this do? Tilda how do you do that?"

In addition, there was some evidence from interviews with students that they had used their connection to look for apprenticeships and/or post-16 college places. Alison was another single parent unable to work because she was suffering from debilitating health problems. Her family's living conditions were cramped. Paul was the eldest of three children living with Alison. His involvement in the scheme perhaps had the most transformative effect of all. As his mother told us, 
“He’s getting everything back and he’s back to his old self again. And schoolwork is now on track, he's positive, he knows what he wants to do when he leaves school. And as far as I'm concerned, from where I'm sat as his mum, that wouldn't have happened without this, and it's made a big improvement in so many ways, so many ways.”

However, despite these positive accounts, we could not argue that this digital inclusion scheme is an unequivocal success story. From the data we have instances of young people engaging in practices to support schoolwork, using the Internet for hobbies, social interactions and career planning. These activities may well have translated into improved social and learning outcomes; and enabled these young people to be more responsible and confident users of the Internet. But this is not the whole story. The laptops were not used regularly across the whole cohort and many families were frustrated by the scheme's significant practical problems. Furthermore, while many were relatively realistic in their hopes for the initiative at the outset, some of the project's original stakeholders, swayed by the compelling digital native rhetoric, anticipated a more significant shift in students’ uses the Internet and broader academic and social outcomes. In reality, the majority of the young people’s engagements with the Internet remained relatively untransformed and few of these young people developed into the highly competent and creative users of the Internet some of the scheme’s more optimistic stakeholders were expecting (Wilkin et al, 2017).

\section{The project's disappointments}

There were many reasons the project failed to live-up to all its promises. These included significant technical problems at its initial set up, delays in fixing connections and laptop problems that occurred throughout the course of the project. The original school leaders engaging with the project also left their respective schools so the research team 
had to take their place in delivering skills training. It could be easy, at this stage, to argue that once these 'practical' problems were addressed that the scheme would have seen more successful. However, many of these issues are common in such projects (Warschauer et al., 2014) and they had been envisaged at the start of the scheme. Furthermore, significant amounts of effort had been put in to mitigate these likely problems. Their resistance to any intervention to prevent the project's sabotage suggests that there is need to move beyond the practical into the theoretical domain.

\section{Theorising the project's disappointments}

We observed common cultures, practices, incentivised behaviours and mind-sets across institutions that are indicative of the project's social and political milieu. A context that many call neoliberalism. Neoliberalism is a contested concept that has only ever existed in messy hybrids (Peck, 2010). Consequently, it can be used as "a sloppy synonym for capitalism” (Peck, 2010, p.1) or, within the lexicon of protest, it is summoned as an ideology that apparently energises "nihilistic free market-loving sociopaths” (Peck, 2010, p. 1) who are blindly committed to the "unethical commercialisation” (Brown, 2015, p. 29) of everything sacred. We have to be careful therefore in defining neoliberalism.

Davies (2016) traces its development from its origins in German post-War liberalism and the liberalism of the Chicago School to its mainstream political adoption in the late 1970s in America and the UK when the state began to organise society and its institutions to conform to the principles of market competition. This included privatisation of public services, such as telecommunications; inviting commercial actors to ‘shake-up’ state monopolies, and the incentivising of private investment into areas and enterprises previously funded by the state. The home access scheme was, in effect, such a public-private partnership. The local council paid the ISP with public money. 
Because neoliberalism valorises such public-private partnerships that imbue the market with ethical potential and social responsibility (Brown, 2015) the scheme looks like a neoliberalist project.

However, this macro definition of neoliberalism fails to help us make sense of all procedural bottlenecks, communication failures, denials of responsibility and unexpected contingencies that frustrated the project's ambitions. No one involved in the project would identify himself or herself as a neoliberal or wanted to the scheme to conform to neoliberalist dogma. For example, many of the teachers viewed the scheme as an opportunity to both support school and social life, wanting the students "to feel part of the same picture that every other student is [in]” (Teacher, School Red). Likewise, one of the lead teachers at School Yellow told us: "Pupil Premium students have many barriers preventing them[...]so giving Internet access and an electronic device was about levelling that playing field in some regard”.

To accomplish deeper insights we adopt Foucault's (2008) ideas to show neoliberalism is less a top-down, coordinated ideological hegemonic project and more a mundane presence in our affective domains that speaks and acts through our languages, purposes and decisions, and social relations. Power becomes a complex, yet very specific form centering on knowledge production through the ensemble of rationalities, strategies, technologies, and techniques concerning the mentality of rule that allow for the de-centering of government through the active role of autoregulated or autocorrecting selves who facilitate 'governance at a distance' (Foucault, 2008). While recognising this form of neoliberalism doesn’t magically explain away all the project’s problems it does allow to us to show the social consequences of marketisation of public services for the providers and the recipients of these services. It also enables us to connect what appears to be small-scale non-generalisable phenomenon to our recent 
socio-economic history of development without summoning neoliberalism as a unitary hegemonic project that conveniently accounts for every agent’s decision. We will explain how this 'mentality of rule' and 'governance at a distance' or 'governmentality' (Foucault, 2008) was manifested in ISP’s and schools' approach to the scheme. As we develop below these neoliberalist conditions, within the ISP and the schools, precluded or inhibited people’s agency: their ability to 'enact the ethical potential and social responsibility’ that neoliberalism often promises.

\section{The ISP}

Once the young people who were eligible for the scheme were identified, the project team held an information meeting in each school and parents were also sent letters about the initiative. At this stage the young people and their families decided whether or not they wished to be part of the scheme. Once signed up, they were sent a second letter from the council explaining the next steps: essentially a meeting where the laptops were given to the students (plus a dongle if requested). Alternatively, the families were given a letter indicating when their broadband set-up would take place.

The ISP (we are calling 'Trojan') was responsible for this set-up visit. Trojan had agreed with the council on the importance of a set-up visit during which parents were to be shown how to access the Internet and control the safety settings on the router and laptop. Trojan charged the local council for each visit but it subcontracted out the service to another company that delivered the equipment to families via post or via a courier service. The subcontractor, however, had little or no prior communication with the families and the 'set-up visit' as conceived by the council and Trojan never occurred. This left families bemused. As one mother said; 
"Because when that (the router) turned up in the post, obviously it had my name on it, it had my address, and I was thinking why have they sent it me, so I was going to take it back to the depot thinking that it was a mistake."

Since there was no set-up visit some families left the router in its box, unused for months as they did not want to break or damage the equipment. There was also no functioning support line for the families to call. Trojan subcontracted out the families' support line to a commercial IT services provider. Calling this number cost the families money and the call handlers had no knowledge of the scheme let alone each family's situation. After the research team complained to Trojan its personnel transferred the helpline to a company that Trojan had recently bought-out. Again, this helpline cost the families and the call handlers had no knowledge of the scheme. It was also a business helpline for business users that maintained the brand name of the company that Trojan had requisitioned. This led families who called the helpline to believe they had been given the wrong number. Moreover, the local council, as account holders, held the usernames and passwords so parents were unable pass the helpline's data protection checks anyway.

Trojan also uses another subsidiary company (which the parent company owns but is branded differently) to provide infrastructure and engineer support. When families reported faults to the research team, we contacted Trojan's representative assigned to the Home Access Scheme who, after warning us the local council would be charged $£ 500$ per visit, dispatched an engineer to the family’s home. If the problem was related to Trojan's equipment but not the cables or the exchange, then the engineer would deny liability and leave the problem unresolved. 
The logic of practice of neoliberalism is to subcontract out constituent parts of an overall service provision to create mini internal markets that (in theory) promote efficiency through competition (Peck, 2010). Within the Home Access Scheme this meant there was no continuity of care as each subcontractor attempted to maximise its revenue or discharge its commitment with the minimum liability. Because the engineer was not permitted to perform operations that were not auditable or sanctioned by the terms of the pre-existing subcontract then he or she would leave the family's home and refer the problem to another service provider within the same parent company. Yet Trojan still charged the local council for the 'service'.

At times, volunteers from Trojan would be willing to visit the family’s homes to try and address problems. These volunteers were potentially able to link across subcontractors. However, this would often take a significant amount of time to organise and was difficult, as these volunteers had very limited understanding of the families who were part of the scheme. We interviewed an experienced former senior regional manager at Trojan who had volunteered for the scheme. He told us, 'I felt personally slightly embarrassed and guilty that for one particular customer it took a couple of weeks over something fairly trivial'. He added 'until you rock up at someone’s house you don’t know what you're going to encounter in terms of the problem that you need to help.' Due to the significant time investment involved in working with the families, and the challenges of still trying to get the technology to work for the family within this complex socio-technical system, the volunteers did not stay on to support the project after the first year.

Because Trojan and its other competitor in our research area have a monopoly on digital communication infrastructure, the local council had no alternative way of delivering the scheme. The council had to channel its money through a corporate actor. 
Thus within neoliberalist arrangements philanthropy only becomes possible if it is 'market conforming' (Peck 2010, p.23). Benevolent state interventions and commercial interests become indivisible as new governmental configurations emerge that 'run in a loop between the market and the state' (Gane, 2013, p.2).

However, these mini-markets could have worked. Neoliberalist organising principles per se did not predetermine the project's failures. With effective project management each company could have shared its data and resources. This was more to do with the subjectification of the families so they became governable within each company's rules of engagement. When it became clear these families did not have standardised needs, Trojan's conditioned response was to avoid incurring cost penalties by repeating procedures and practices that had already failed.

This is typical of “neoliberalism’s articulation” as it emerges "through endlessly unfolding failures and successes in the relations between peoples and their socially constructed realities” (Springer, 2012, p.137). These relations are then ‘(re)imagined, (re)interpreted, and (re) assembled to influence forms of knowledge through the conduct of conduct' (Springer, 2012, p.137). In effect, this meant because their procedures failed to address the family's needs, within Trojan's operating culture, rather than its procedures and mentality, the families became the problem.

Trojan’s actors in this scheme had only narrow parameters of conduct available to them. There was no capacity for flexibility or ability de-commodify the families. This led to a fragmentation of responsibility in deference to commercial outcomes. Which meant helping the families by operating outside the normal terms of service was noone’s responsibility. There were people working within Trojan who cared about the project and volunteered to help families out. However, they couldn't make an effective contribution within Trojan's rigid systems of support. The discursive construction of the 
families as artefacts of the market seemed to normalise this inflexibility. There was no facility in Trojan's lexicon or procedures to acknowledge the families as potentially vulnerable. The moral obligations that some members of Trojan acknowledged were erased by the company’s language of subjectification. Families were referred to by usernames, or by service jargon such as ‘end user’ that distanced Trojan’s staff from the plight of the families: they became glitches in the system or even sources of revenue rather than vulnerable people. This all led us to believe Trojan's involvement in the scheme was more a marketing strategy aligned with discourses around responsible capitalism.

This position was not unique to Trojan. We approached a competitor who 'performed' philanthropic interest only to withdraw from the scheme when they saw low numbers offering little revenue and marketing potential. We can infer from each of company’s actions the scheme's families were not investable - there was no incentive to keep them happy because was no obvious prospect of a future return for the business. We could only conclude the culture of these organisations and its governance systems as evidenced in the actions and language of their agents just wasn't able to support such as scheme as this. This has important implications any scheme that intends to address digital inequality that we will take-up in our conclusion.

\section{The schools}

Because we have more evidence the teachers wanted to make this scheme work the situation in the schools was less straightforward. Teachers viewed the scheme positively; not just an opportunity primarily to address deficits in the students' academic performance but also to develop their social skills, identity, and well-being. As a teacher at school Blue told us, the Internet can be 'one of the best tools you can possibly have, for things like research and doing your homework’. In contrast to Trojan, the schools 
were acutely aware they were working with vulnerable families and/or low or middle attainers. For two reasons, this knowledge became part of the scheme's difficulties. Firstly, despite its goal to improve grades, the scheme was marginalised to prioritise academic attainment. And secondly, notwithstanding the scheme's aim to develop the students' confidence online, the schools prioritised their duty of care over the students' digital autonomy. Ostensibly, these outcomes seem reasonable. However, the neoliberalist conditions within which state schools in England (Welsh and Scottish schools are controlled by their respective devolved government) operate made these decisions less a positive choice and more a compromised, defensive response to avoid recriminations. To understand why, this scheme needs to be situated in its broader policy context.

There are over 3,300 academy schools in England now that come directly under the Department of Education's control. It is difficult to centrally manage standards in this many schools. It requires many strategies, technologies, and techniques that facilitate 'governance at a distance’ Foucault (2008) which include targets, audits, and sanctions. All state funded secondary schools in England are financed per pupil. Schools that fail to show their students are making progress or that are unable to, for example, meet attendance or exclusion targets can be subjected to disciplinary inspections that could lead to a series of interventions and sanctions or even the school's closure. The league tables, published annually in newspapers (and on their websites), data published on the inspectorate's website and on the Government's Department for Education and Skills’ website are a public record of each schools’ performance. The logic of neoliberalism is that opening collectively held resources like schools to market mediation engenders greater efficiency: hence the valorisation of consumer choice and league tables to inform that choice and the policy to drive up standards by making 
failure visible. Thus, ensuring all students demonstrate good progress is essential to the success and survival of a school.

Some of the students on the scheme were middle attainers. There was relentless pressure on them to achieve $\mathrm{C}$ grades in Maths, English and Science - subjects that are central to a school's headline performance in tables and inspections. In school Red for example, this translated into the school colonising students' free time in exchange for further stress - as the exert from one of our interviews shows:

Sam (Mum): “In Maths she’s struggling.”

Clara: “Well I am, I'm on a D.”

Sam (indignantly): "It’s not a C!"

Sam (sympathetically): “But they're doing so much. I mean, when you sent the text [to arrange the interview] I thought, "Oh God, is that a day she's going to be at home?" Sometimes she doesn't get home 'til five o'clock and I don't even give that a thought. And she's going in on Saturday mornings.....I don't understand. You know, there's so much pressure on them now and so many mocks, by the time they actually come to do the proper exams they're going to be blown out."

Clara: "And then I don't get time to eat or just relax really." Clara is also an aspiring dancer but she had no choice but to stop dancing to prioritise her Maths. This focus on target grades for specific subjects meant many students stopped ICT classes at the end of year 9 (aged 13) or earlier. As Tammy from school Blue told us:

“They (the school) stopped that (ICT) ... I don't know how long, I haven't done IT since I was in like Year 7 and 8 I think.”

Elsbi is a young woman from an Afro-Caribbean background whose mother was working nightshifts as a nurse. As a relatively high attainer with a strong educational 
ethos, Elsbi was planning on doing 'A' levels (qualifications necessary to get to university) in school Red. But even she had little to do with technology in school as this exchange in one of our interviews shows:

Interviewer: “So you're doing A level Business, but you haven’t done any ICT for years and you don't get any help with your computer skills in school now?” Elsbi: “Not really except for those sessions that [Name of Researcher] used to come in... But that's not really... We did one control assessment on the computer but you just have to type it up on Word."

While national targets are intended to concentrate teachers' efforts on identifying and responding to struggling students who need their help the most (Hargreaves, 2009), these targets can dominate teacher practice. Teachers interpellate the metrics used to measure student progress into their affective domains and day-today routines: they become auto-regulated or auto-correcting selves who facilitate the 'governance at a distance’ (Foucault, 2008) that is necessary to oversee schools.

Teachers are incentivised to pursue solutions for 'rapid improvements that will keep the forces of accountability at bay’ (Datnow, Park, \& Wohlstetter, 2007). Instead of seeing the scheme as a way to enhance academic progress, it was ultimately positioned as a distraction.

Moreover, teachers' incentives, pay, and job security have all become interdependent. Ultimately, the lead teachers simply were unable to offer the regular skills training sessions that had been initially agreed at the project's outset. In part, this was because these activities were not in any way integrated into by their work plans, job description, or performance management: it was something they were asked to do on top of their daily responsibilities. Some teachers also became disillusioned by Trojan’s failure to uphold its commitments. Thus, despite the teachers in the scheme having 
positive attitudes towards it, in reality it was difficult for them to make it part of their daily practice. The research team therefore took over the delivery of the one-to-one skills sessions but this meant that they were, in effect, 'outside' of the school system. As attainment pressures in the spring term intensified in the scheme's final quarter, the research team lost contact with the schools entirely as senior management teams ended the series of one-to-one sessions prematurely because they wanted students to focus solely on their exams. The schools were only morally obligated to participate in the scheme and therefore their on-going commitment relied entirely on the lead teachers having the time and the management support to continue fulfilling their original commitments. The scheme was not integrated into any of the school's regimes of accountability and withdrawal from the scheme had no publically visible consequences. The individual at the council who spearheaded the scheme left and was not replaced and this, combined with the 'academy' ${ }^{3}$ status of the schools, made any kind of accountability within the project structure very difficult.

Lazzarato (2009) says institutions operating within neoliberalist conditions are dominated by 'micro-politics of little fears' (Lazzarato, 2009, p.120). This helps explain why the schools prioritised exams and why the scheme didn’t deliver its other core promise to help its young people feel socially confident and integrated. Despite the research teams best efforts, heavy filters were employed at schools Red and Blue that ensured safety was maintained. As Martha from school Red told us:

“You know there's lot that's blocked[...] All those websites, you can't go on Facebook, you can't go on Soundcloud. One week you'll be able to use this thing and then the next week it's blocked. And it keeps going more and more."

\footnotetext{
${ }^{3}$ Schools in England with academy status are no longer accountable to local authority control and instead receive their funding directly from the Department of Education.
} 
These filters restricted the possible ways that the young people could use the laptops for entertainment and social life, all of which are important for a broader social and educational agenda: including use of social media. Thus, contrary to the teachers' wider social interest in the scheme, and wanting students to 'feel part of the same picture'. The fear of failure and its consequences superseded the project's goals.

\section{Conclusion}

Because the families on the scheme had very few of sources of economic, cultural and social capital they lacked the power of choice. They were unable choose a different service provider for their Internet connection. They were unaware they could bring regulatory pressure to bear on Trojan by, for example, complaining to Ofcom (the UK's Internet service regulator) to demand a better service. Consequently, choices were imposed on them by systems of neoliberal governance. Similarly, the schools had often narrowed-down their investment in the scheme's young people to just getting a C grade in Maths. The schools chose the students' priorities for them. But these parents were unable to choose a different school for their child. We said in our introduction the global network society is 'a choice, a choice made by some and working in the interest of some” (Biesta, 2013, p.734). Many of the families on this scheme were barely participating in this global network society - using pay-as-go phones to just go on Facebook for example. However, this scheme didn't fall short owing to 'the some' who were 'working in the interest of the some'. It was unable to deliver its early promise because Trojan and the schools were governed by neoliberalist systems that only really work for individuals who have the power and privilege to exercise their choice.

Acknowledgements: The authors of this paper would like to thank Dr Tracey Calabrese, Dr Laura Hakimi, and Ms Laura Pinkerton for their assistance with this project. 


\section{References}

Bennett, S., Maton, K., \& Kervin, L. (2008). The “digital natives” debate: A critical review of the evidence. British Journal of Educational Technology, 39(5), 775786. http://doi.org/10.1111/j.1467-8535.2007.00793.x

Biesta, G. (2013). Responsive or responsible? Democratic education for the global networked society. Policy Futures in Education, 11(6), 733-744. http://doi.org/10.2304/pfie.2013.11.6.733

Bourdieu, P. (1992). The logic of practice. Studies in philosophy and education. ..., CA: Stanford University Press.

boyd, d. (2014). It's complicated: The social lives of networked teens. New Haven, CT: Yale University Press.

Brown, W. (2015). Undoing Demos. Cambridge, MA: MIT Press.

Datnow, A., Park, V., \& Wohlstetter, P. (2007). Achieving with data: How highperforming school systems use data to improve instruction for elementary students. [incomplete reference]

Davies, C., \& Eynon, R. (2013). Teenagers and technology. Hove: Routledge.

Davies, W. (2016). The limits of neoliberalism: Authority, sovereignty and the logic of competition. London: Sage.

Dean, M. (1999). Governmentality: Power and rule in modern society. London: Sage.

Dey, I. (2003). Qualitative data analysis: A user friendly guide for social scientists. London: Routledge.

Facer, K., \& Furlong, R. (2001). Beyond the Myth of the "Cyberkid”: Young People at the Margins of the Information Revolution. Journal of Youth Studies, 4(4), 451469.

Foucault, M. (2008). The Birth of Biopolitics: Lectures at the Collège de France, 19781979. Palgrave Macmillan. 
Hargittai, E. (2010). Digital Na(t)ives? Variation in Internet Skills and Uses among Members of the “Net Generation.” Sociological Inquiry, 80(1), 92-113. http://doi.org/10.1111/j.1475-682X.2009.00317.x

Hargittai, E., \& Shaw, A. (2014). Mind the skills gap: the role of Internet know-how and gender in differentiated contributions to Wikipedia. Information, Communication \& Society, 18(4), 424-442. http://doi.org/10.1080/1369118X.2014.957711

Hargreaves, H. (2009). A decade of educational change and a defining moment of opportunity- an introduction. Journal of Educational Change, 10, 89-100.

Helsper, E. J., \& Eynon, R. (2010). Digital natives: where is the evidence? British Educational Research Journal, 36(3), 503-520. http://doi.org/10.1080/01411920902989227

Jewitt, C., \& Parashar, U. (2011). Technology and learning at home: findings from the evaluation of the Home Access Programme pilot. Journal of Computer Assisted Learning, 27(4), 303-313.

Lazzarato, M. (2009). Neoliberalism in Action: Inequality, Insecurity and the Reconstitution of the Social. Theory, Culture \& Society, 26(6), 109-133. http://doi.org/10.1177/0263276409350283

Lievrouw, L. A., \& Farb, S. E. (2003). Information and equity. Annual Review of Information Science and Technology, 37(1), 499-540.

Livingstone, S., \& Helsper, E. (2007). Gradations in digital inclusion: children, young people and the digital divide. New Media and Society, 9(4), 671-696. http://doi.org/10.1177/1461444807080335

Miles, M. B., \& Huberman, A. M. (1984). Qualitative data analysis: A sourcebook of new methods. Sage Publications.

Peck, J. (2010). Constructions of Neoliberal Reason. Oxford: Oxford University Press.

Pillow, W. S. (2003). Confession, catharsis, or cure? Rethinking the uses of reflexivity as methodological power in qualitative research. International Journal of 
Qualitative Research in Education, 16, 175-196.

Robinson, L., Cotten, S. R., Ono, H., Quan-Haase, A., Mesch, G., Chen, W., ... Stern, M. J. (2015). Digital inequalities and why they matter. Information, Communication \& Society, 18(5), 569-582. http://doi.org/10.1080/1369118X.2015.1012532

Selwyn, N. (2014a). Distrusting Educational Technology. London: Routledge.

Selwyn, N. (2014b). Making the most of the "micro": revisiting the social shaping of micro-computing in UK schools. Oxford Review of Education, 40(2), 170-188.

Springer, S. (2012). Neoliberalism as discourse: between Foucauldian political economy and Marxian poststructuralism. Critical Discourse Studies, 9(2), 133147. http://doi.org/10.1080/17405904.2012.656375

Stake, R. E. (1995). The Art of Case Study Research. London: Sage Publications.

Swanborn, P. (2010). Case Study Research: What, why and how? London: Sage Publications.

Walling, J. (2009). The Challenges of in-depth interviewing with disadvantaged respondents. In E. Hargittai (Ed.), Research confidential: Solutions to problems most social scientists pretend they never have. University of Michigan Press.

Wilkin, S., Davies, H \& Eynon R. (2017) Addressing digital inequalities amongst young people: conflicting discources and complex outcomes. Oxford Review of Education. In press.

Wyn, J., \& White, R. (1997). Rethinking Youth. St Leonards: Allen \& Unwin. 